\title{
The effects of $\mathrm{N}$-acetyl cysteine on the MG132 proteasome inhibitor-treated lung cancer cells in relation to cell growth, reactive oxygen species and glutathione
}

\author{
YONG HWAN HAN, HWA JIN MOON, BO RA YOU, SUNG ZOO KIM, SUHN HEE KIM and WOO HYUN PARK
}

Department of Physiology, Medical School, Centers for Healthcare Technology Development Institute for Medical Sciences, Chonbuk National University, JeonJu 561-180, Republic of Korea

Received September 29, 2009; Accepted January 22, 2010

DOI: 10.3892/ijmm_00000389

\begin{abstract}
MG132 as a proteasome inhibitor has been shown to induce apoptotic cell death through formation of reactive oxygen species (ROS). Here, we investigated the effects of $\mathrm{N}$-acetyl cysteine (NAC; a well-known antioxidant), Lbuthionine sulfoximine (BSO; an inhibitor of GSH synthesis) or diethyldithiocarbamate (DDC; an inhibitor of $\mathrm{Cu} / \mathrm{Zn}-\mathrm{SOD}$ ) on MG132-treated Calu-6 or A549 lung cancer cells in relation to cell growth, ROS and GSH levels. MG132 inhibited the growth of Calu-6 and A549 cells at 24 h. MG132 induced apoptosis in both cell lines, which was accompanied by the loss of mitochondrial membrane potential (MMP; $\Delta \Psi_{\mathrm{m}}$ ). ROS levels including $\mathrm{O}_{2}{ }^{-}$were increased in both MG132-treated lung cells. MG132 also induced GSH depletion in both lung cell types. Treatment with $10 \mu \mathrm{M}$ BSO or $1 \mu \mathrm{M}$ DDC affected ROS and GSH levels in MG132-treated Calu-6 cells. However, these changes did not influence cell growth and death in the cells. NAC prevented cell growth inhibition and death in MG132-treated lung cells, which was accompanied by decreased ROS, but not by decreased GSH depletion. In conclusion, the changes of ROS and GSH by MG132, NAC, $\mathrm{BSO}$ or DDC were partially related to cell growth and death in the lung cancer cell lines Calu-6 and A549.
\end{abstract}

Correspondence to: Dr Woo Hyun Park, Department of Physiology, Medical School, Centers for Healthcare Technology Development Institute for Medical Sciences, Chonbuk National University, JeonJu 561-180, Republic of Korea

E-mail: parkwh71@chonbuk.ac.kr

Abbreviations: MG132, carbobenzoxy-Leu-Leu-leucinal; ROS, reactive oxygen species; SOD, superoxide dismutase; $\operatorname{MMP}\left(\Delta \Psi_{\mathrm{m}}\right)$, mitochondrial membrane potential; FBS, fetal bovine serum; FITC, fluorescein isothiocyanate; $\mathrm{H}_{2}$ DCFDA, 2',7'-dichlorodihydrofluorescein diacetate; DHE, dihydroethidium; GSH, glutathione; CMFDA, 5-chloromethylfluorescein diacetate; MTT, 3-(4,5dimethylthiazol-2-yl)-2,5-diphenyltetrazolium bromide; NAC, Nacetyl cysteine; BSO; L-buthionine sulfoximine, DDC; diethyldithiocarbamate

Key words: MG132, apoptosis, lung cancer, N-acetyl cysteine, reactive oxygen species

\section{Introduction}

The ubiquitin-proteasomal system represents the major non-lysosomal pathway through which intracellular proteins involved in cell cycling, proliferation, differentiation and apoptosis are degraded in eukaryotic cells $(1,2)$. The inhibition of proteasome function has emerged as a useful strategy to maneuver apoptosis. MG132 (carbobenzoxy-Leu-Leu-leucinal) as a peptide aldehyde effectively blocks the proteolytic activity of proteasome complex (3). Proteasome inhibitors including MG132 have been shown to induce apoptotic cell death through formation of reactive oxygen species (ROS) $(4,5)$. ROS formation and GSH (glutathione) depletion due to proteasome inhibitors may cause mitochondrial dysfunction and subsequent cytochrome $\mathrm{c}$ release, which leads to cell viability loss $(6,7)$. The mechanism underlying ROS generation after inhibition of proteasome is still unclear.

Lung cancer is a major contributor to the variety cancer death in developed countries. Various novel therapeutic strategies are currently under consideration, as the clinical use of cytotoxic drugs is limited due to intrinsic or acquired resistance and toxicity (8). Studies of the molecular mechanisms of cytotoxic drug action have shed light on the treatment of lung cancer, and novel agents that target specific intracellular pathways related to the distinctive properties of cancer cells continue to be developed. However, the relationship among proteasome inhibition, ROS and GSH in lung cancer cells still remains obscure.

Because MG132 treatment inhibited the growth of lung cancer cells (Calu-6 and A549) via inducing the cell cycle arrest as well as triggering apoptosis (unpublished data), in the present study we investigated the effects of $\mathrm{N}$-acetyl cysteine (NAC; a well-known antioxidant), L-buthionine sulfoximine [BSO; an inhibitor of GSH synthesis (9)] or diethyldithiocarbamate [DDC; an inhibitor of $\mathrm{Cu} / \mathrm{Zn}$-SOD (10)] on MG132-treated Calu-6 or A549 cells in relation to the changes of cell growth, ROS and GSH levels.

\section{Materials and methods}

Cell culture. The human pulmonary adenocarcinoma Calu-6 and A549 cell lines were obtained from ATCC and maintained in a humidified incubator containing $5 \% \mathrm{CO}_{2}$ at $37^{\circ} \mathrm{C}$. Lung cancer cells were cultured in RPMI-1640 supplemented 
with $10 \%$ fetal bovine serum (FBS) and $1 \%$ penicillinstreptomycin (Gibco BRL, Grand Island, NY). Cells were routinely grown in 100-mm plastic tissue culture dishes (Nunc, Roskilde, Denmark) and harvested with a solution of trypsinEDTA while in a logarithmic phase of growth. Cells were maintained in these culture conditions for all experiments.

Reagents. MG132 was purchased from Calbiochem (San Diego, CA). This agent was dissolved in DMSO solution at $10 \mathrm{mM}$ as a stock solution. N-acetylcysteine (NAC) was obtained from Sigma. NAC was dissolved in the buffer [20 mM HEPES (pH 7.0)] at $100 \mathrm{mM}$ as a stock solution. L-buthionine sulfoximine (BSO) and diethyldithiocarbamate (DDC) were also obtained from Sigma. These agents were dissolved in water or ethanol at $100 \mathrm{mM}$ as a stock solution. Cells were pretreated with NAC, BSO or DDC for 30 min prior to treatment with MG132. Based on previous experiments, $10 \mu \mathrm{M}$ MG132 was chosen as a suitable dose to differentiate the levels of cell growth inhibition or death in the presence or absence of NAC, BSO or DDC. NAC ( $2 \mathrm{mM}), 10 \mu \mathrm{M}$ BSO and $1 \mu \mathrm{M}$ DDC were used as optimal doses in this experiment. DMSO $(0.4 \%)$ and ethanol $(0.2 \%)$ were used as a control vehicle. All stock solutions were wrapped in foil and kept at $-20^{\circ} \mathrm{C}$.

Cell growth assay. The effect of drugs on lung cancer cell growth was determined by measuring 3-(4,5-dimethylthiazol2-yl)-2,5-diphenyltetrazolium bromide (MTT) dye absorbance of living cells as previously described (11). In brief, cells $\left(5 \times 10^{4}\right.$ cells per well) were seeded in 96-well microtiter plates. After cells were exposed to $10 \mu \mathrm{M}$ MG132 with or without $2 \mathrm{mM}$ NAC, $10 \mu \mathrm{M}$ BSO or $1 \mu \mathrm{M}$ DDC for $24 \mathrm{~h}, 20 \mu \mathrm{l}$ of MTT (Sigma) solution ( $2 \mathrm{mg} / \mathrm{ml}$ in PBS) was added to each well of 96-well plates. The plates were incubated for 4 additional hours at $37^{\circ} \mathrm{C}$. MTT solution in the medium was aspirated off and $200 \mu 1$ of DMSO were added to each well to solubilize the formazan crystals formed in viable cells. Optical density was measured at $570 \mathrm{~nm}$ using a microplate reader (Spectra MAX 340, Molecular Devices Co., Sunnyvale, CA).

Annexin V staining. Apoptosis was determined by staining cells with annexin V-fluorescein isothiocyanate (FITC) $(\mathrm{Ex} / \mathrm{Em}=$ $488 \mathrm{~nm} / 519 \mathrm{~nm}$ ) as previously described (12). In brief, $1 \times 10^{6}$ cells in $60 \mathrm{~mm}$ culture dish (Nunc) were incubated with $10 \mu \mathrm{M}$ MG132 with or without $2 \mathrm{mM}$ NAC, $10 \mu \mathrm{M}$ BSO or $1 \mu \mathrm{M}$ DDC for $24 \mathrm{~h}$. Cells were washed twice with cold PBS and then resuspended in $500 \mu 1$ of binding buffer (10 mM HEPES/ $\mathrm{NaOH} \mathrm{pH} 7.4,140 \mathrm{mM} \mathrm{NaCl}, 2.5 \mathrm{mM} \mathrm{CaCl}_{2}$ ) at a concentration of $1 \times 10^{6}$ cells $/ \mathrm{ml}$. Five microliters of annexin V-FITC (PharMingen, San Diego, CA) was then added to these cells, which were analyzed with a FACStar flow cytometer (Becton-Dickinson).

Measurement of mitochondrial membrane potential (MMP) $\left(\Delta \Psi_{m}\right)$. The MMP $\left(\Delta \Psi_{\mathrm{m}}\right)$ levels were measured by the Rhodamine 123 fluorescent dye $(E x / E m=485 \mathrm{~nm} / 535 \mathrm{~nm})$, as previously described (13). In brief, $1 \times 10^{6}$ cells in $60 \mathrm{~mm}$ culture dish (Nunc) were incubated with $10 \mu \mathrm{M}$ MG132 with or without $2 \mathrm{mM}$ NAC, $10 \mu \mathrm{M}$ BSO or $1 \mu \mathrm{M}$ DDC for $24 \mathrm{~h}$. Cells were washed twice with PBS and incubated with
Rhodamine $123(0.1 \mu \mathrm{g} / \mathrm{ml}$; Sigma $)$ at $37^{\circ} \mathrm{C}$ for $30 \mathrm{~min}$. Rhodamine 123 staining intensity was determined by flow cytometry. Rhodamine 123 negative cells indicate the loss of $\operatorname{MMP}\left(\Delta \Psi_{\mathrm{m}}\right)$ in lung cancer cells.

Detection of intracellular $\mathrm{ROS}$ and $\mathrm{O}_{2}^{--}$levels. Intracellular ROS such as $\mathrm{H}_{2} \mathrm{O}_{2},{ }^{\circ} \mathrm{OH}$ and $\mathrm{ONOO}^{\bullet}$ were detected by means of an oxidation-sensitive fluorescent probe dye, 2',7'-dichlorodihydrofluorescein diacetate $\left(\mathrm{H}_{2} \mathrm{DCFDA}\right)$ (Invitrogen Molecular Probes, Eugene, OR) as previously described (14). $\mathrm{H}_{2}$ DCFDA $(\mathrm{Ex} / \mathrm{Em}=495 \mathrm{~nm} / 529 \mathrm{~nm})$ is poorly selective for superoxide anion radical $\left(\mathrm{O}_{2}{ }^{-}\right)$. In contrast, dihydroethidium (DHE) $(\mathrm{Ex} / \mathrm{Em}=518 \mathrm{~nm} / 605 \mathrm{~nm}$; Invitrogen Molecular Probes) is a fluorogenic probe that is highly selective for $\mathrm{O}_{2}{ }^{-}$among

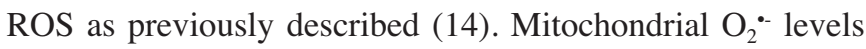
were detected using MitoSOX ${ }^{\mathrm{TM}}$ Red mitochondrial $\mathrm{O}_{2}{ }^{-}$ indicator $(E x / E m=510 \mathrm{~nm} / 580 \mathrm{~nm}$; Invitrogen Molecular Probes) as previously described (14). In brief, $1 \times 10^{6}$ cells in $60 \mathrm{~mm}$ culture dish (Nunc) were incubated with $10 \mu \mathrm{M}$ MG132 with or without $2 \mathrm{mM}$ NAC, $10 \mu \mathrm{M}$ BSO or $1 \mu \mathrm{M}$ DDC for $24 \mathrm{~h}$. Cells were then washed in PBS and incubated with $20 \mu \mathrm{M} \mathrm{H}_{2}$ DCFDA, $20 \mu \mathrm{M}$ DHE or $5 \mu \mathrm{M} \mathrm{MitoSOX}^{\mathrm{TM}}$ Red at $37^{\circ} \mathrm{C}$ for $30 \mathrm{~min}$ according to the instructions of the manufacturer. DCF, DHE and MitoSOX Red fluorescences were detected using a FACStar flow cytometer (BectonDickinson). ROS and $\mathrm{O}_{2}{ }^{-*}$ levels were expressed as mean fluorescence intensity (MFI), which was calculated by CellQuest software.

Detection of the intracellular glutathione (GSH). Cellular GSH levels were analyzed using 5-chloromethylfluorescein diacetate (CMFDA, Molecular Probes) $(\mathrm{Ex} / \mathrm{Em}=522 \mathrm{~nm} / 595 \mathrm{~nm})$ as previously described (14). In brief, $1 \times 10^{6}$ in $60 \mathrm{~mm}$ culture dish (Nunc) cells were incubated with $10 \mu \mathrm{M}$ MG132 with or without $2 \mathrm{mM}$ NAC, $10 \mu \mathrm{M}$ BSO or $1 \mu \mathrm{M}$ DDC for $24 \mathrm{~h}$. Cells were then washed with PBS and incubated with $5 \mu \mathrm{M}$ CMFDA at $37^{\circ} \mathrm{C}$ for $30 \mathrm{~min}$ according to the instructions of the manufacturer. CMF fluorescence intensity was determined using a FACStar flow cytometer (Becton-Dickinson). Negative CMF staining (GSH depleted) cells were expressed as the percent of (-) CMF cells. CMF levels in cells except GSH depleted cells were expressed as mean fluorescence intensity (MFI), which was calculated by CellQuest software.

Statistical analysis. The results shown represent the mean of at least three independent experiments; bar, SD. The data were analyzed using Instat software (GraphPad Prism4, San Diego, CA). The Student's t-test or one-way analysis of variance (ANOVA) with post hoc analysis using Tukey's multiple comparison test was used for parametric data. The statistical significance was defined as $\mathrm{P}<0.05$.

\section{Results}

Effects of NAC, BSO and DDC on cell growth, apoptosis and $\operatorname{MMP}\left(\Delta \Psi_{m}\right)$ in MG132-treated Calu-6 cells. We examined the effect of NAC, BSO and DDC on the growth of MG132treated Calu- 6 cells using the MTT assay. Treatment with $10 \mu \mathrm{M}$ MG132 inhibited the growth of Calu- 6 cells about 
A

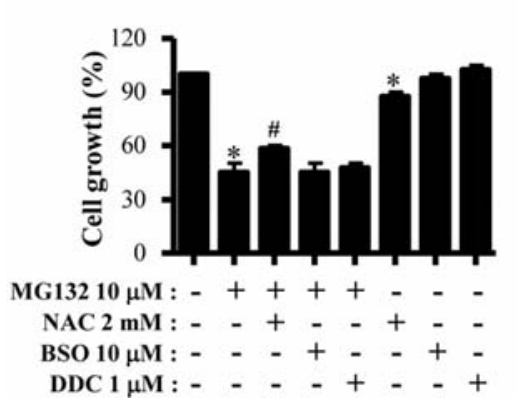

B

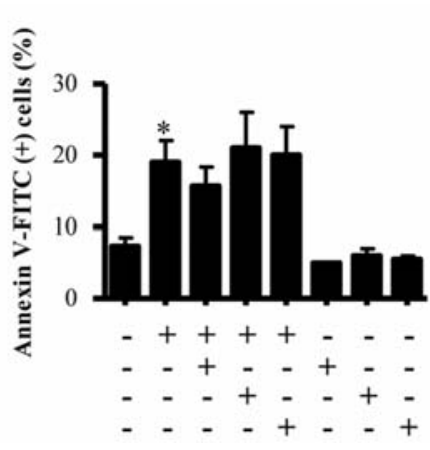

C

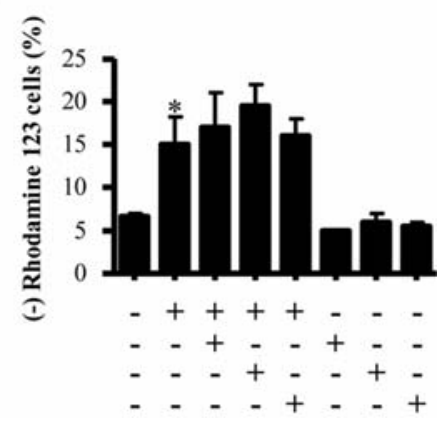

Figure 1. Effects of NAC, BSO or DDC on cell growth, apoptosis and MMP $\left(\Delta \Psi_{\mathrm{m}}\right)$ in MG132-treated Calu-6 cells. Exponentially-growing cells were treated with $10 \mu \mathrm{M}$ MG132 for $24 \mathrm{~h}$ following $30 \mathrm{~min}$ pre-incubation of $2 \mathrm{mM}$ NAC, $10 \mu \mathrm{M}$ BSO or $1 \mu \mathrm{M}$ DDC. (A) Cell growth was assessed by the MTT assay. (B) and (C) Graphs show the percents of Annexin V positive staining cells (B) and Rhodamine 123 negative [MMP ( $\left.\Delta \Psi_{\mathrm{m}}\right)$ loss] cells (C) compared with MG132-untreatred Calu-6 control cells, as measured with a FACStar flow cytometer. ${ }^{*} \mathrm{P}<0.05$ compared with the control group. ${ }^{\#} \mathrm{P}<0.05$ compared with cells treated with MG132 only.

A

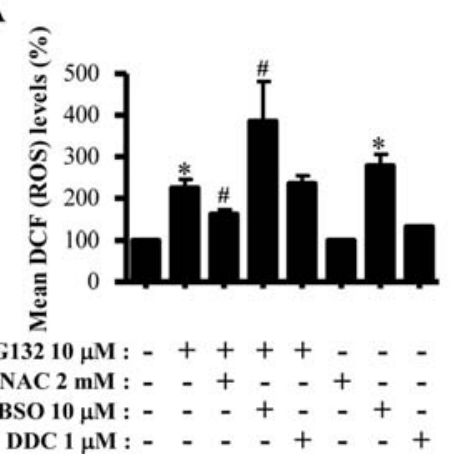

B

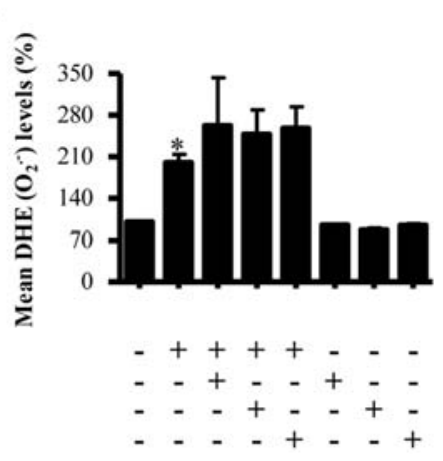

C

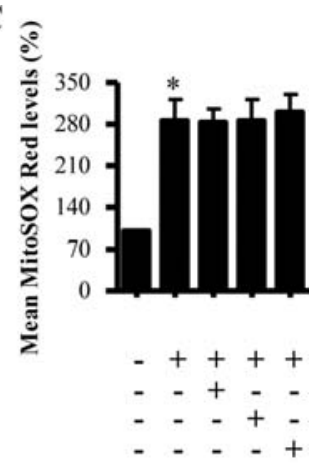

Figure 2. Effects of NAC, BSO or DDC on ROS levels in MG132-treated Calu- 6 cells. Exponentially-growing cells were treated with $10 \mu \mathrm{M}$ MG132 for $24 \mathrm{~h}$ following $30 \mathrm{~min}$ pre-incubation of $2 \mathrm{mM} \mathrm{NAC,} 10 \mu \mathrm{M}$ BSO or $1 \mu \mathrm{M}$ DDC. ROS levels in Calu- 6 cells were measured using a FACStar flow cytometer. Graphs indicate DCF (ROS) levels (\%) (A), DHE $\left(\mathrm{O}_{2}{ }^{*}\right)$ levels (\%) (B) and MitoSOX Red (mitochondrial $\mathrm{O}_{2}{ }^{\circ}$ ) levels (\%) compared with MG132-untreatred Calu-6 control cells $(\mathrm{C}) .{ }^{*} \mathrm{P}<0.05$ compared with the control group. ${ }^{*} \mathrm{P}<0.05$ compared with cells treated with MG132 only.

$55 \%$ at $24 \mathrm{~h}$ (Fig. 1A). Treatment with NAC but not BSO and DDC significantly prevented the growth inhibition of MG132-treated Calu-6 cells (Fig. 1A).

In the current study, we observed that $10 \mu \mathrm{M}$ MG132 induced apoptosis in Calu- 6 at $24 \mathrm{~h}$, as evidenced by annexin V staining cells (Fig. 1B). We determined whether NAC, BSO or DDC changes MG132-induced apoptosis in Calu-6 cells. The MTT results indicated that, only NAC decreased the number of annexin V-FITC positive cells in MG132-treated Calu-6 cells (Fig. 1B).

Apoptosis is closely related to the collapse of MMP $\left(\Delta \Psi_{\mathrm{m}}\right)$ (15). Therefore, we determined the loss of MMP $\left(\Delta \Psi_{\mathrm{m}}\right)$ in MG132-treated Calu-6 cells. As expected, the loss of MMP $\left(\Delta \Psi_{\mathrm{m}}\right)$ was observed in MG132-treated cells at $24 \mathrm{~h}$ (Fig. 1C). However, none of NAC, BSO and DDC changed MMP $\left(\Delta \Psi_{\mathrm{m}}\right)$ loss levels in MG132-treated cells (Fig. 1C).

Effects of NAC, BSO and DDC on ROS and GSH levels in MG132-treated Calu-6 cells. Next, we determined whether the levels of intracellular ROS in MG132-treated Calu- 6 cells were changed by treatment with NAC, BSO and DDC at $24 \mathrm{~h}$. Intracellular ROS (DCF) level such as $\mathrm{H}_{2} \mathrm{O}_{2}$ was increased in MG132-treated Calu-6 cells (Fig. 2A). Treatment with NAC decreased ROS level in MG132-treated cells (Fig. 2A). BSO treatment strongly increased ROS level in MG132-treated and -untreated cells (Fig. 2A). DDC did not change ROS level in MG132-treated cells but slightly increased ROS level in control cells (Fig. 2A). When we detected the intracellular $\mathrm{O}_{2}{ }^{--}$levels in MG132-treated Calu-6 cells, red fluorescence derived from DHE reflecting intracellular $\mathrm{O}_{2}{ }^{--}$level was increased in these cells (Fig. 2B). Treatment with NAC, BSO and DDC intensified $\mathrm{O}_{2}{ }^{-}$levels in MG132-treated cells but the increase was not significant (Fig. 2B). Furthermore, MitoSOX Red fluorescence level, which specifically indicates $\mathrm{O}_{2}^{--}$levels in the mitochondria, was increased in MG132treated Calu-6 cells (Fig. 2C). NAC, BSO and DDC did not strongly affect the mitochondrial $\mathrm{O}_{2}{ }^{-}$level in MG132-treated cells (Fig. 2C).

Next, we analyzed the changes of GSH levels in Calu-6 cells at $24 \mathrm{~h}$. Treatment with MG132 increased the number of GSH depleted cells about 7\% compared with control cells (Fig. 3A). NAC, BSO and DDC did not alter the number in MG132-treated Calu-6 cells (Fig. 3A). DDC slightly induced GSH depletion in Calu-6 control cells (Fig. 3A). When CMF (GSH) level in Calu-6 cells was assessed, MG132 increased the GSH level (Fig. 3B). Treatment with NAC and BSO 
A

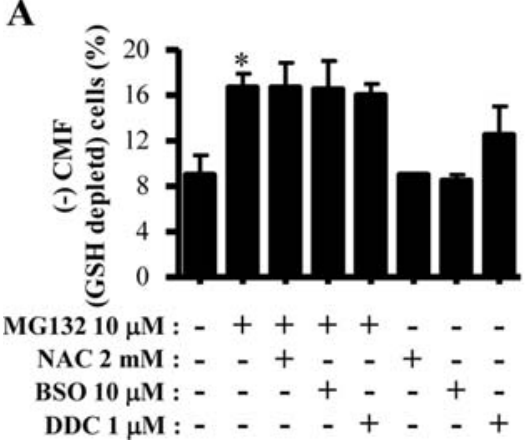

B

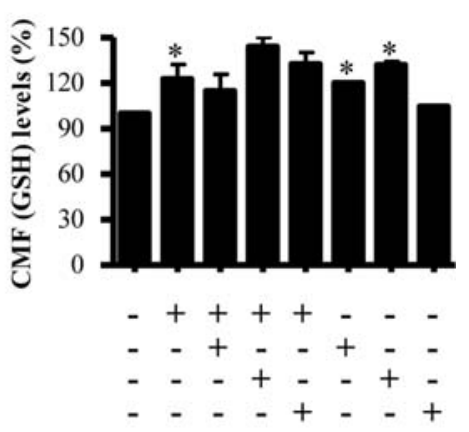

Figure 3. Effects of NAC, BSO or DDC on GSH levels in MG132-treated Calu- 6 cells. Exponentially-growing cells were treated with $10 \mu \mathrm{M}$ MG132 for 24 h following $30 \mathrm{~min}$ pre-incubation of $2 \mathrm{mM}$ NAC, $10 \mu \mathrm{M}$ BSO or $1 \mu \mathrm{M}$ DDC. GSH levels in Calu- 6 cells were measured using a FACStar flow cytometer. Graphs indicate (-) CMF (GSH depleted) cells (\%) (A) and mean CMF (GSH) levels (\%) compared with MG132-untreatred Calu-6 control cells (B). *P<0.05 compared with the control group. ${ }^{\#} \mathrm{P}<0.05$ compared with cells treated with MG132 only.
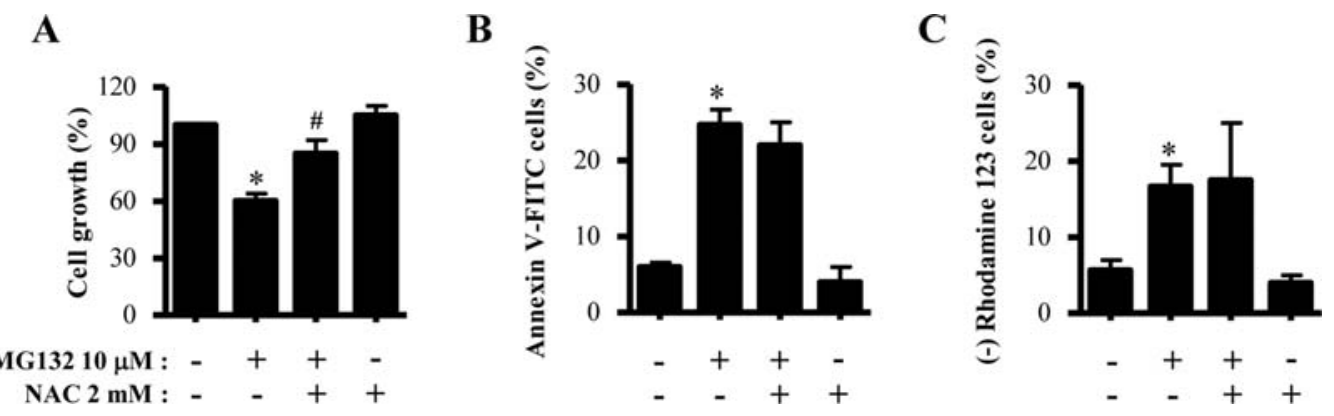

Figure 4. Effects of NAC on cell growth, apoptosis and MMP $\left(\Delta \Psi_{\mathrm{m}}\right)$ in MG132-treated A549 cells. Exponentially-growing cells were treated with $10 \mu \mathrm{M}$ MG132 for $24 \mathrm{~h}$ following 30 min pre-incubation of 2 mM NAC. (A) Cell growth was assessed by the MTT assay. (B) and (C) Graphs show the percents of Annexin V positive staining cells (B) and Rhodamine 123 negative [MMP $\left(\Delta \Psi_{\mathrm{m}}\right)$ loss] cells (C) compared with MG132-untreated A549 control cells, as measured with a flow cytometer. ${ }^{*} \mathrm{P}<0.05$ compared with the control group. ${ }^{\#} \mathrm{P}<0.05$ compared with cells treated with MG132 only.

slightly decreased and increased GSH level in MG132treated cells, respectively (Fig. 3B). NAC and BSO increased GSH level in MG132-untreated control cells (Fig. 3B).

Effects of NAC on cell growth, apoptosis, MMP $\left(\Delta \Psi_{m}\right)$ in MG132-treated A549 cells. Additionally, we examined the effect of MG132 and/or NAC on the growth of other lung cancer cell line, A549. Treatment with $10 \mu \mathrm{M}$ MG132 inhibited the growth of A549 cells about $50 \%$ at 24 h (Fig. 4A). Treatment with NAC significantly reduced the growth inhibition of MG132-treated A549 cells (Fig. 4A). In addition, MG132 induced apoptosis in A549 cells (Fig. 4B). NAC slightly decreased the number of annexin V-FITCpositive cells induced by MG132 (Fig. 4B). As MMP $\left(\Delta \Psi_{\mathrm{m}}\right)$ loss in MG132-treated Calu- 6 cells, MG132 triggered the loss of MMP $\left(\Delta \Psi_{\mathrm{m}}\right)$ in A549 cells (Fig. 4C). NAC did not change the level of loss (Fig. 4C).

Effects of NAC on ROS and GSH levels in MG132-treated A549 cells. Next, we determined the effect of MG132 and/or NAC on ROS and GSH levels in A549 cells at 24 h. Intracellular ROS (DCF) level was increased in MG132-treated A549 cells (Fig. 5A). Treatment with NAC decreased ROS level in these cells (Fig. 5A). In addition, $\mathrm{O}_{2}{ }^{-}$level in MG132treated A549 cells was increased (Fig. 5B). NAC did not significantly change $\mathrm{O}_{2}{ }^{--}$level in these cells (Fig. 5B). When we analyzed the changes of GSH levels in A549 cells, MG132 increased the number of GSH depleted cells about $7 \%$ compared with control cells (Fig. 5C). NAC did not affect GSH depletion level in MG132-treated A549 cells (Fig. 5C). In addition, MG132 slightly reduced GSH level in A549 cells (Fig. 5D). NAC did not change the GSH level in MG132-treated cells but strongly reduced the GSH level in MG132-untreated control cells (Fig. 5D).

\section{Discussion}

In the present study, we focused on evaluating the effects of NAC, BSO or DDC on MG132-treated lung cancer cells in relation to cell growth, ROS and GSH, since we have observed that MG132 inhibited the growth of lung cancer Calu-6 and A549 cells. We also observed that MG132 induced apoptosis in lung cancer cells. Treatment with NAC, but not BSO and DDC significantly prevented the growth inhibition of MG132-treated Calu-6 cells and slightly decreased the number of annexin V-FITC-positive cells in these cells. In addition, NAC significantly reduced the growth inhibition of MG132-treated A549 cells and weakly decreased the number of annexin V-FITC-positive cells. These data suggest that the pretreatment with NAC but not BSO and DDC is involved in pathways of cell growth inhibition and cell death in lung cancer cells. 
A

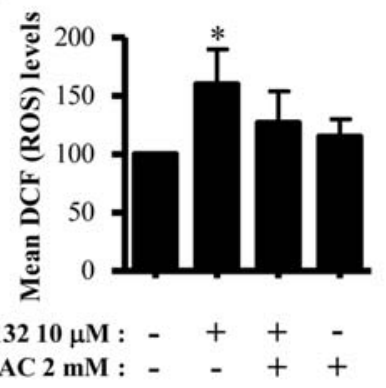

C

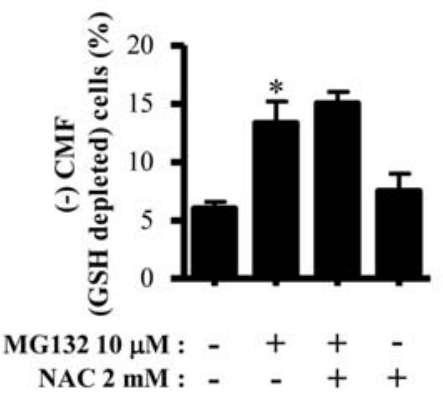

B

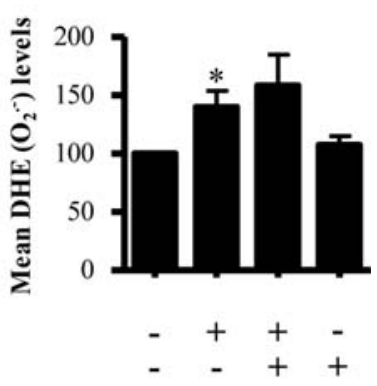

D

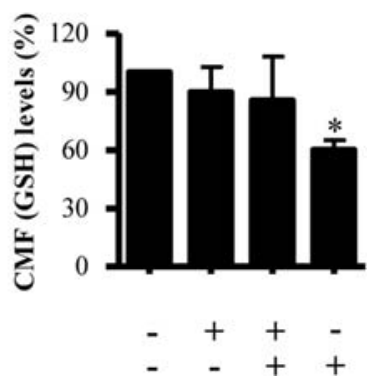

Figure 5. Effects of NAC on ROS and GSH levels in MG132-treated A549 cells. Exponentially-growing cells were treated with $10 \mu \mathrm{M}$ MG132 for 24 h following 30 min pre-incubation of 2 mM NAC. ROS and GSH levels in A549 cells were measured using a flow cytometer. Graphs indicate DCF (ROS) levels (\%) (A), DHE $\left(\mathrm{O}_{2}^{*}\right.$ ) levels (\%) (B), (-) CMF (GSH depleted) cells (\%) (C) and mean CMF (GSH) levels (\%) compared with MG132-untreated A549 control cells $(\mathrm{D}) .{ }^{*} \mathrm{P}<0.05$ compared with the control group.

Proteasome inhibitors including MG132 have been shown to induce apoptotic cell death through formation of ROS (4-6,16,17). According to our results, the intracellular ROS including $\mathrm{O}_{2}^{--}$were increased in MG132-treated Calu-6 and A549 cells. It is reported that ROS formation due to proteasome inhibitors may cause mitochondrial dysfunction and subsequent cytochrome $\mathrm{c}$ release, which leads to cell viability loss $(6,7)$. The collapse of MMP $\left(\Delta \Psi_{\mathrm{m}}\right)$ occurs during apoptosis (15). Correspondingly, MG132 significantly induced the loss of MMP $\left(\Delta \Psi_{\mathrm{m}}\right)$ in both lung cancer cell lines. NAC, BSO and DDC did not change the loss of MMP $\left(\Delta \Psi_{\mathrm{m}}\right)$ in MG132treated lung cells. These results imply that the loss of MMP $\left(\Delta \Psi_{\mathrm{m}}\right)$ following treatment with MG132 leads to apoptosis, and NAC, BSO or DDC is not directly involved in the loss of $\operatorname{MMP}\left(\Delta \Psi_{\mathrm{m}}\right)$. Furthermore, mitochondrial $\mathrm{O}_{2}{ }^{-}$levels in Calu-6 cells were increased by MG132. Although the mechanism underlying ROS generation after MG132 treatment is not clearly explained, our results suggest that increased $\mathrm{O}_{2}{ }^{--}$in MG132-treated lung cells mainly originates from the mitochondria influenced by it. When we determined whether the levels of intracellular ROS in MG132-treated lung cells were changed by treatment with NAC, BSO or DDC, treatment with NAC showing the reduction of annexin V-FITC-positive cells in MG132-treated lung cells decreased ROS (DCF) level but not $\mathrm{O}_{2}{ }^{-}$level in these cells. BSO intensified the increased ROS level but not the $\mathrm{O}_{2}{ }^{-}$level in MG132-treated Calu- 6 cells. However, this enhancement of ROS level did not exaggerate cell death level in these cells. In general, the inhibition of SOD by DDC (10) in cells leads to an increase in ROS including $\mathrm{O}_{2}{ }^{\circ-}$. According to our results, DDC treatment did not affect
ROS (DCF) levels in MG132-treated Calu-6 cells but slightly increased the $\mathrm{O}_{2}{ }^{-}$level in these cells. These phenomena were not accompanied by alternation of cell growth and death levels in these cells. These data suggest that the changes of ROS levels by MG132 are partially related to the death of lung cancer cells, and ROS (DCF level) is more involved in cell death mechanism than $\mathrm{O}_{2}{ }^{-}$(DHE level). The relationship between ROS and ubiquitin-proteasomal systems in lung cell survival or cell death signaling still remains an open question.

It has been reported that the intracellular GSH content has a decisive effect on anticancer drug-induced apoptosis, indicating that apoptotic effects are inversely comparative to GSH content (18-20). The redox state of cellular GSH is an important modulatory element in the protein ubiquitination pathways (21). It is reported that GSH depletion due to proteasome inhibitors may lead to cell death $(6,7)$. Likewise, our result demonstrated that treatment with MG132 increased the number of GSH depleted cells in the lung cancer cell lines. Treatment with NAC did not significantly affect GSH depletion in MG132-treated lung cancer cells. However, we observed that NAC slightly prevented GSH depletion in MG132-treated HeLa cells, which is accompanied by the reduction of annexin $\mathrm{V}$ positive cells and MMP $\left(\Delta \Psi_{\mathrm{m}}\right)$ loss in these cells (unpublished data). BSO as a GSH synthesis inhibitor also did not enhance GSH depletion in MG132-treated Calu-6 cells. However, in antimycin A-treated Calu-6 cells, BSO intensified GSH depletion and apoptosis (unpublished data). It is possible that the effect of NAC and BSO on intracellular GSH contents is dependent of cell types or co-treated agents. It is of note that CMF (GSH) level in MG132-treated Calu-6 cells were increased. Probably, the increased GSH 
level occurred in response to the increasing ROS produced by MG132 treatment, and some Calu- 6 cells beyond their capacity to resist ROS insults would die. In case of MG132treated A549 cells, GSH level was weakly decreased. Consequently, this might increase ROS levels in this cell line. NAC increased GSH level in Calu- 6 control cells but strongly decreased the level in A549 cells. Particularly, treatment with $10 \mu \mathrm{M}$ BSO increased GSH levels in MG132treated and -untreated Calu- 6 cells. Other reports definitely show that $100 \mu \mathrm{M}$ and $1 \mathrm{mM}$ BSO decreased GSH level in MCF breast cancer cells (22) and U937 leukemia cells (23), respectively. According to our recent reports, treatment with 1 or $10 \mu \mathrm{M}$ BSO significantly enhanced GSH depletion in arsenic trioxide-treated A549 (24) and HeLa cells (25). These data also suggest that NAC and BSO differently influence GSH levels depending on cell types or the incubation doses. Collectively, our data suggest that the intracellular GSH content has a decisive role on anticancer drug-induced cell death, but changes of the content are not sufficient to predict cell death correctly.

In summary, MG132 induced growth inhibition and death of lung cancer cells accompanied by increasing ROS level as well as triggering of GSH depletion. The changes of ROS and GSH levels by BSO or DDC did not strongly affect cell growth and death in MG132-treated Calu-6 cells. NAC prevented the growth inhibition and death in MG132-treated lung cells, which was accompanied by decreased ROS (DCF), but not by decreased GSH depletion. Conclusively, the changes of ROS and GSH by MG132, NAC, BSO or DDC were partially related to the growth and death of human lung cancer Calu-6 and A549 cells. Our present data could provide useful information for the action of MG132, a proteasome inhibitor in lung cancer cells in relation to cell growth, ROS and GSH levels.

\section{Acknowledgements}

This research was supported by a grant of the Korea Healthcare Technology R\&D Project, Ministry for Health, Welfare and Family Affairs, Republic of Korea (A084194) and the Korea Research Foundation Grant funded by the Government of the Republic of Korea (MOEHRD).

\section{References}

1. Orlowski RZ: The role of the ubiquitin-proteasome pathway in apoptosis. Cell Death Differ 6: 303-313, 1999.

2. Voges D, Zwickl P and Baumeister W: The 26S proteasome: a molecular machine designed for controlled proteolysis. Annu Rev Biochem 68: 1015-1068, 1999.

3. Lee DH and Goldberg AL: Proteasome inhibitors: valuable new tools for cell biologists. Trends Cell Biol 8: 397-403, 1998.

4. Wu HM, Chi KH and Lin WW: Proteasome inhibitors stimulate activator protein-1 pathway via reactive oxygen species production. FEBS Lett 526: 101-105, 2002.

5. Perez-Galan P, Roue G, Villamor N, Montserrat E, Campo E and Colomer D: The proteasome inhibitor bortezomib induces apoptosis in mantle-cell lymphoma through generation of ROS and Noxa activation independent of p53 status. Blood 107: 257-264, 2006

6. Ling YH, Liebes L, Zou Y and Perez-Soler R: Reactive oxygen species generation and mitochondrial dysfunction in the apoptotic response to Bortezomib, a novel proteasome inhibitor, in human H460 non-small cell lung cancer cells. J Biol Chem 278 33714-33723, 2003.
7. Qiu JH, Asai A, Chi S, Saito N, Hamada H and Kirino T: Proteasome inhibitors induce cytochrome c-caspase-3-like protease-mediated apoptosis in cultured cortical neurons. J Neurosci 20: 259-265, 2000.

8. Petty RD, Nicolson MC, Kerr KM, Collie-Duguid E and Murray GI: Gene expression profiling in non-small cell lung cancer: from molecular mechanisms to clinical application. Clin Cancer Res 10: 3237-3248, 2004.

9. Bailey HH: L-S,R-buthionine sulfoximine: historical development and clinical issues. Chem Biol Interact 111-112: 239-254, 1998.

10. Cocco D, Calabrese L, Rigo A, Argese E and Rotilio G: Reexamination of the reaction of diethyldithiocarbamate with the copper of superoxide dismutase. J Biol Chem 256: 8983-8986, 1981.

11. Park WH, Seol JG, Kim ES, Hyun JM, Jung CW, Lee CC, Kim BK and Lee YY: Arsenic trioxide-mediated growth inhibition in MC/CAR myeloma cells via cell cycle arrest in association with induction of cyclin-dependent kinase inhibitor, p21, and apoptosis. Cancer Res 60: 3065-3071, 2000.

12. Han YH, Kim SZ, Kim SH and Park WH: Apoptosis in pyrogallol-treated Calu- 6 cells is correlated with the changes of intracellular GSH levels rather than ROS levels. Lung Cancer 59: 301-314, 2008.

13. Han YH, Kim SZ, Kim SH and Park WH: Arsenic trioxide inhibits growth of As4.1 juxtaglomerular cells via cell cycle arrest and caspase-independent apoptosis. Am J Physiol Renal Physiol 293: F511-F520, 2007.

14. Han YH, Kim SH, Kim SZ and Park WH: Caspase inhibitor decreases apoptosis in pyrogallol-treated lung cancer Calu-6 cells via the prevention of GSH depletion. Int $\mathrm{J}$ Oncol 33: 1099-1105, 2008.

15. Yang J, Liu X, Bhalla K, Kim CN, Ibrado AM, Cai J, Peng TI, Jones DP and Wang X: Prevention of apoptosis by Bcl-2: release of cytochrome c from mitochondria blocked. Science 275: 1129-1132, 1997.

16. Wu HM, Wen HC and Lin WW: Proteasome inhibitors stimulate interleukin-8 expression via Ras and apoptosis signal-regulating kinase-dependent extracellular signal-related kinase and c-Jun $\mathrm{N}$-terminal kinase activation. Am J Respir Cell Mol Biol 27: 234-243, 2002.

17. Emanuele S, Calvaruso G, Lauricella M, Giuliano M, Bellavia G, D'Anneo A, Vento R and Tesoriere G: Apoptosis induced in hepatoblastoma HepG2 cells by the proteasome inhibitor MG132 is associated with hydrogen peroxide production, expression of Bcl-XS and activation of caspase-3. Int J Oncol 21: 857-865, 2002.

18. Estrela JM, Ortega A and Obrador E: Glutathione in cancer biology and therapy. Crit Rev Clin Lab Sci 43: 143-181, 2006.

19. Higuchi Y: Glutathione depletion-induced chromosomal DNA fragmentation associated with apoptosis and necrosis. J Cell Mol Med 8: 455-464, 2004.

20. Park WH, Han YW, Kim SH and Kim SZ: A superoxide anion generator, pyrogallol induces apoptosis in As4.1 cells through the depletion of intracellular GSH content. Mutat Res 619: 81-92, 2007.

21. Jahngen-Hodge J, Obin MS, Gong X, Shang F, Nowell TR Jr, Gong J, Abasi H, Blumberg J and Taylor A: Regulation of ubiquitin-conjugating enzymes by glutathione following oxidative stress. J Biol Chem 272: 28218-28226, 1997.

22. Lewis-Wambi JS, Kim HR, Wambi C, Patel R, Pyle JR, KleinSzanto AJ and Jordan VC: Buthionine sulfoximine sensitizes antihormone-resistant human breast cancer cells to estrogeninduced apoptosis. Breast Cancer Res 10: R104, 2008.

23. Ramos AM and Aller P: Quercetin decreases intracellular GSH content and potentiates the apoptotic action of the antileukemic drug arsenic trioxide in human leukemia cell lines. Biochem Pharmacol 75: 1912-1923, 2008.

24. Han YH, Kim SZ, Kim SH and Park WH: Induction of apoptosis in arsenic trioxide-treated lung cancer A549 cells by buthionine sulfoximine. Mol Cells 26: 158-164, 2008.

25. Han YH, Kim SZ, Kim SH and Park WH: Enhancement of arsenic trioxide-induced apoptosis in HeLa cells by diethyldithiocarbamate or buthionine sulfoximine. Int J Oncol 33: 205-213, 2008. 